\title{
The first reported case of Burkholderia contaminans in patients with cystic fibrosis in Ireland: from the Sargasso Sea to Irish Children
}

Rachel F. Power ${ }^{1,2}$, Barry Linnane ${ }^{1,2}$, Ruth Martin², Noelle Power ${ }^{2}$, Peig Harnett ${ }^{2}$, Brian Casserly ${ }^{1,2}$, Nuala H. O'Connell ${ }^{1,2}$ and Colum P. Dunne ${ }^{1 *}$

\begin{abstract}
Background: Burkholderia contaminans is an emerging pathogen in the cystic fibrosis (CF) setting. Included in the Burkholderia cepacia complex (Bcc), B. contaminans is a Gram negative, motile, obligate aerobe previously classified as a pseudomonad. Previous reports have described B. contaminans isolation from patients in Portugal, Switzerland, Spain, Argentina and the USA. This, however, is the first report relating to $B$. contaminans affecting Irish patients with $C F$, initially detected in a paediatric setting.

Case presentation: Burkholderia contaminans was identified in the routine analysis of sputum from a fourteen year old boy, at his annual review and subsequently from the sputum from his 19 year old brother. RecA gene sequencing and pulsed field gel electrophoresis (PFGE) were unable to distinguish between the isolates, which demonstrated with susceptibility to ciprofloxacin, cotrimoxazole, meropenem, pipercillin/tazobactam and ceftazidime. Both isolates were resistant to aztreonam, with reduced susceptibility to tobramycin. Following treatment with intravenous meropenem and ceftazidime, oral ciprofloxacin and nebulised tobramycin for 6 weeks, sputum specimens from both patients were negative for B. contaminans. No other member of the local CF cohort proved positive.

Conclusions: Bcc bacteria are associated with poor prognosis in CF and decreased life expectancy, specifically leading to a more rapid decline in lung function and, in some cases, to a fatal necrotizing pneumonia known as the "cepacia syndrome". Some species exhibit innate resistance to multiple antimicrobial agents and their transmission rate can be high in susceptible patients. In that context, we describe the first incidence of CF-related $B$. contaminans in Ireland and its successful eradication from two patients, one paediatric, using an aggressive antimicrobial regimen.
\end{abstract}

Keywords: Burkholderia contaminans, Cystic fibrosis, First incidence, Ireland, Case report

\footnotetext{
* Correspondence: colum.dunne@ul.ie

${ }^{1}$ Graduate Entry Medical School and Centre for Interventions in Infection,

Inflammation \& Immunity (4i), University of Limerick, Limerick, Ireland

Full list of author information is available at the end of the article
} 


\section{Background}

Burkholderia cepacia complex (Bcc) is a grouping of bacteria comprising at least 17 species capable of infecting susceptible patients including the immunocompromised and those with cystic fibrosis (CF) [1, 2]. Burkholderia contaminans is one such species, first identified as a contaminant of a marine-derived nucleic acid sample obtained from the Sargasso Sea [3, 4]. Burkholderia contaminans is increasingly associated with CF [5-11] although not exclusively as other hospitalised non-CF patients have also been affected [9, 12-14].

Globally, Ireland has the highest prevalence of CF (a recessive autosomal disease associated with increased susceptibility to respiratory infection) with prevalence of 2.98 per 10,000 compared to European and USA prevalence of 0.737 and 0.797 per 10,000 , respectively [15]. In that context, this first detection of B. contaminans in any Irish patient and, especially CF patients, is noteworthy. In this report, similar to other studies involving B. contaminans, we attempt to correlate colonisation with incidence of acute exacerbation of symptoms. In addition, we describe the outcomes of molecular typing of the isolates, using $r e c A$ sequencing and pulsed field gel electrophoresis (PFGE) techniques successfully employed elsewhere [6, 16, 17]. As B. contaminans is emerging as an identifiable, discrete pathogen described previously as "virtually impossible to eradicate from the CF lung, posing a serious clinical threat" [8] and is currently without definitive guidelines for antimicrobial sensitivity/resistance, we detail our antimicrobial susceptibility testing, and the successful eradication of B. contaminans from both patients using an aggressive treatment regimen.

\section{Case presentation}

In August 2013, two male CF patients, siblings aged 14 and 19 were identified as Burkholderia contaminans positive at University Hospital, Limerick, Ireland (where the first Irish CF-related multidrug-resistant Bordetella petrii was identified) [18]. Retrospective analyses of patient charts and stored sputum samples determined frequency of hospitalisation, episodes of infections, and antimicrobial use prior to $B$. contaminans detection and throughout treatment. Emphasis was placed on presence/absence of clinical features during treatment, in particular lung function, efficacy of antimicrobial therapy and patient outcome.

Genotypically, Patients A (aged 14) and B (19 years) are homozygous for the F 508del mutation (within the CF transmembrane conductance regulator causing loss of the amino acid phenylalanine, affecting chloride ion channels in cell membranes and leading to production of thickened mucus). Both resided in the family home in the Midwest of Ireland.
Between diagnosis as a neonate and August 2013, 14 year old Patient A had experienced four admissions for treatment of exacerbations of CF, complicated by reactive airways disease with persistent cough and poor compliance with his medications and adherence to physiotherapy. Prior to August 2013, his cough swabs and sputum cultures had yielded Staphylococcus aureus, Haemophilus parainfluenzae, Candida species and Aspergillus fumigatus. He had also acquired, and had been treated for, Pseudomonas aeruginosa in 2008, which recurred in 2012. Attempts to eradicate $P$. aeruginosa failed and he was deemed to be chronically infected in November 2012. As the strain was resistant to tobramycin, he was commenced on long-term anti-pseuodomonad therapy comprising alternate months of two mega-units of nebulised colistin twice daily with $75 \mathrm{mg}$ of nebulised aztreonam three times daily, along with oral azithromycin $250 \mathrm{mg}$ once daily taken three times per week. Struggling with adherence, his Forced Expiratory Volume in $1 \mathrm{~s}\left(\mathrm{FEV}_{1}\right)$ dropped from 62 \% in August 2012 to 46 \% in June 2013.

On 6th August 2013, Patient A presented for annual review. Staphylococcus aureus and $P$. aeruginosa were identified from his routine sputum sample. In addition, however, Burkholderia contaminans was also detected, representing the first such incidence in Ireland. Patient A's $\mathrm{FEV}_{1}$ was $38 \%$, his lowest recorded. His full blood count at the time showed a mildly elevated white cell count of $10.4510^{9} / \mathrm{L}$, with a neutrophil count of $5.8610^{9} / \mathrm{L}$.

Between diagnosis as a neonate and August 2013, 19 year old Patient B had also demonstrated poor compliance with his treatment regimen, complicated by insulin dependent diabetes mellitus and pulmonary fibrosis. Like his younger brother, Patient B's cough swabs and sputum cultures had consistently yielded varying and mixed species: $H$. parainfluenzae, $H$. influenzae, S. aureus, Streptococcus pneumoniae, and A. fumigatus. In 2007, he acquired Pseudomonas aeruginosa (tobramycin resistant) and, despite multiple attempts at eradication, he became chronically infected. His $\mathrm{FEV}_{1}$ fluctuated between 17 and $95 \%$ throughout this time, with a baseline of $68 \%$. His antimicrobial medications included oral azithromycin $250 \mathrm{mg} 3$ days per week and two mega-units nebulised colistin twice daily, on alternate months.

On 2nd July 2013, Patient B was admitted with an infective exacerbation and was treated with a course of intravenous meropenem ( 2 g every $8 \mathrm{~h}$ ) and tobramycin (480 mg once daily) combined with intense physiotherapy. He was also provided nutritional support for a body mass index of 17 . Two days after detection of B. contaminans in Patient A's sputum, his brother was confirmed as positive.

Microbiological analysis was comprehensive, utilising $r e c A$ sequencing and pulsed field gel electrophoresis (PFGE). More specifically, following growth of bacteria 
on "Burkholderia cepacia specific agar" (LIP Diagnostics, Fannin Healthcare, Ireland), identification was confirmed by Matrix-Assisted Laser-Desorption/Ionization TimeOf-Flight Mass Spectrometry (MALDI-TOF MS) and samples forwarded to the Antimicrobial Resistance and Healthcare Associated Infections Reference Unit (AMRHAI, Public Health England) for confirmation by amplification of the recA gene using the BCR1 and BCR2 primers described previously [19]. Pulsed-field gel electrophoresis (PFGE) of $\mathrm{XbaI}$-digested genomic DNA was also performed. Both methods indicated presence of a single discrete $B$. contaminans strain.

Currently, there is no definitive classification of $B$. contaminans as sensitive/resistant to specific antimicrobials. In this study, the efficacy of selected antimicrobials against the $B$. contaminans isolates was initially assessed using Etest $^{\oplus}$ (bioMérieux, France) test strips to ascertain minimum inhibitory concentrations (MIC): aztreonam MIC $>256 \mathrm{mg} / \mathrm{L}$; meropenem $\mathrm{MIC}=2.0 \mathrm{mg} / \mathrm{L}$; colistimethate $>256 \mathrm{mg} / \mathrm{L}$; tobramycin $=64 \mathrm{mg} / \mathrm{L}$; ciprofloxacin $=1 \mathrm{mg} / \mathrm{L}$; pipercillin/tazobactam MIC $>256 \mathrm{mg} / \mathrm{L}$; and ceftazidime $\mathrm{MIC}=8 \mathrm{mg} / \mathrm{L}$. Both isolates were sent to the UK CF microbiology reference laboratory at the Freeman Hospital (Newcastle upon Tyne) for synergy testing (i.e., determining the optimal antimicrobial combinations to eradicate infection). A combination of tobramycin and meropenem achieved only inhibition of growth, while combinations of ceftazidime with meropenem, ciprofloxacin, and tobramycin proved bactericidal.

It was decided to adopt a 6 week quadruple treatment strategy comprising IV ceftazidime $50 \mathrm{mg}$ per $\mathrm{kg}$ per dose every $8 \mathrm{~h}$, IV meropenem $40 \mathrm{mg}$ per kg per dose [to a maximum of $2 \mathrm{~g}$ per dose], oral ciprofloxacin $15 \mathrm{mg}$ per $\mathrm{kg}$ per dose bd, and nebulised tobramycin $300 \mathrm{mg}$ bd. However, Patient A discontinued meropenem at 3 weeks as a consequence of developing severe back and muscle pain, a reaction that was reported to the Regulatory Agency. $\mathrm{He}$ completed treatment with the remaining three antimicrobials and his $\mathrm{FEV}_{1}$ improved from 38 to $61 \%$. He was subsequently treated with nebulised aztreonam and colistimethate, alternating monthly for a year. Patient B successfully completed the initial regimen over 6 weeks, with similar improvement reflected in an cumulative increase in $\mathrm{FEV}_{1}$ of $26 \%$ over the subsequent 1 year period, along with an increase in weight from $54 \mathrm{~kg}$ in July 2013 to $61.9 \mathrm{~kg}$ in September 2014. Burkholderia contaminans has been eradicated successfully from both patients, and they remain free of infection 30 months post treatment. Both patients now demonstrate increased adherence to treatment and physiotherapy, with sustained improved lung function.

At the time of $B$. contaminans detection, Patient A was attending the paediatric clinic while his brother was admitted to the adult CF clinic. The clinics are located in separate areas of the hospital. However, upon identification of the pathogen, the local Bcc infection control policy was implemented and the brothers were segregated from all other CF patients. Containment appears to have been effective as $B$. contaminans has not been detected in our hospital since.

\section{Conclusions}

Species of the Burkholderia cepacia complex are associated with opportunistic infection in patients with $\mathrm{CF}$, and are associated with a worse prognosis and decreased life expectancy [10]. One such bacterium is B. contaminans that, since first identification in 2009, has become recognized as ubiquitous in the environment $[20,21]$, including healthcare facilities where it has caused outbreaks $[12,14,22]$. However, the discrete impact of $B$. contaminans is poorly understood as, firstly, its incidence is typically reported as part of multi-bacterial infections [10] and, secondly, its presence may not have been identified at all pre-2009 or, since then, the species incorrectly identified using available molecular techniques [23]. Indeed, it is noticeable that recent studies of B. contaminans have, in many cases, focused on development of accurate and more sophisticated molecular characterization of the species including mechanisms mediating its pathogenicity [5, 24-26]. However, it is somewhat ironic that some of those studies are focused on developing novel antimicrobial/antifungal agents produced by $B$. contaminans [27-29].

In this report, we describe the first clinical incidence of B. contaminans in Ireland. As with others, our observation related to $C F$ patients, one of whom was a child. Given the high prevalence of CF in Ireland, and the increasingly frequent isolation of $B$. contaminans from $\mathrm{CF}$ patients in some countries (e.g., [11], our reaction to identification of the pathogen for the first time was one of extreme prudence. Our empiric, and subsequently targeted, antimicrobial treatment regimen was deliberately aggressive, as was our Bcc infection control policy. Ultimately, both proved effective, resulting in eradication of the Burkholderia strain from the two patients and containment of the potential risk to other CF patients attending the hospital.

Further, given the current lack of defined guidelines regarding $B$. contaminans antimicrobial susceptibilities, we present our MIC data (detailing resistance to aztreonam and tobramycin and susceptibility to ciprofloxacin, cotrimoxazole, meropenem, pipercillin/tazobactam and ceftazidime) to supplement results published recently from Switzerland [30]. We hope that our descriptions of the cases and our successful treatment choices will prove useful to clinicians encountering $B$. contaminans and prove beneficial to them and their patients. 


\section{Ethics approval and consent to participate} Ethical approval to report this case was not required.

\section{Consent for publication}

Written informed consent was obtained from the patients and their parents for publication in this case report. A copy of the written consent is available for review by the Editor of this journal.

\section{Availability of data and materials}

There are no additional data. The bacterial isolates involved in this case can be shared.

\section{Abbreviations \\ CF: cystic fibrosis; PFGE: pulsed field gel electrophoresis; FEV $_{1}$ : forced expiratory volume in one second; MIC: minimum inhibitory concentration.}

\section{Competing interests}

The authors declare that they have no competing interests.

\section{Authors' contributions}

$R P, B L, N O^{\prime} C, L C, N P$ and $P H$ were responsible for treating the patients. $B L$, $N O^{\prime} C$ and $C D$ recognised the novelty of the case and drafted the manuscript. $\mathrm{NO}^{\prime} \mathrm{C}$ and RM were responsible for the microbiology analysis. RP, $B L$ and CD drafted the manuscript. All authors read and approved the manuscript.

\section{Acknowledgements}

The authors are grateful to the staff of the microbiology labs at University Hospital Limerick for their work in supporting treatment of the children in this case.

\section{Funding}

No funding was received for this work.

\section{Author details}

${ }^{1}$ Graduate Entry Medical School and Centre for Interventions in Infection, Inflammation \& Immunity (4i), University of Limerick, Limerick, Ireland. ${ }^{2}$ University Hospital Limerick, Dooradoyle, Limerick, Ireland.

Received: 22 February 2016 Accepted: 12 April 2016

Published online: 22 April 2016

\section{References}

1. Mahenthiralingam E, Urban TA, Goldberg JB. The multifarious, multireplicon Burkholderia cepacia complex. Nat Rev Microbiol. 2005;3(2):144-56.

2. Vandamme P, Dawyndt P. Classification and identification of the Burkholderia cepacia complex: past, present and future. Syst Appl Microbiol. 2011;34(2):87-95.

3. Venter JC, Remington K, Heidelberg JF, Halpern AL, Rusch D, Eisen JA, Wu D, Paulsen I, Nelson KE, Nelson W, et al. Environmental genome shotgun sequencing of the Sargasso Sea. Science. 2004;304(5667):66-74.

4. Mahenthiralingam E, Baldwin A, Drevinek P, Vanlaere E, Vandamme P, LiPuma JJ, Dowson CG. Multilocus sequence typing breathes life into a microbial metagenome. PLoS One. 2006;1:e17.

5. Bloodworth RA, Selin C, Lopez De Volder MA, Drevinek P, Galanternik L, Degrossi J, Cardona ST. Draft genome sequences of Burkholderia contaminans, a Burkholderia cepacia complex species that is increasingly recovered from cystic fibrosis patients. Genome Announc. 2015;3(4):e00766-15

6. Martina P, Bettiol M, Vescina C, Montanaro P, Mannino MC, Prieto Cl, Vay C, Naumann D, Schmitt J, Yantorno O, et al. Genetic diversity of Burkholderia contaminans isolates from cystic fibrosis patients in Argentina. J Clin Microbiol. 2013:51(1):339-44

7. Barrado L, Martinez MT, Villa J, Orellana MA, Viedma E, Chaves F. Clonal diversity among Burkholderia cepacia complex isolates from cystic fibrosis patients in a reference unit. Enferm Infecc Microbiol Clin. 2013;31(10):665-8.

8. Coutinho CP, Dos Santos SC, Madeira A, Mira NP, Moreira AS, Sa-Correia I. Long-term colonization of the cystic fibrosis lung by Burkholderia cepacia complex bacteria: epidemiology, clonal variation, and genome-wide expression alterations. Front Cell Infect Microbiol. 2011:1:12. doi:10.3389/ fcimb.2011.00012. eCollection 2011.

9. Peterson AE, Chitnis AS, Xiang N, Scaletta JM, Geist R, Schwartz J, Dement J, Lawlor E, Lipuma JJ, O'Connell H, et al. Clonally related Burkholderia contaminans among ventilated patients without cystic fibrosis. Am J Infect Control. 2013;41(12):1298-300.

10. Coutinho CP, Barreto C, Pereira L, Lito L, Melo Cristino J, Sa-Correia I. Incidence of Burkholderia contaminans at a cystic fibrosis centre with an unusually high representation of Burkholderia cepacia during 15 years of epidemiological surveillance. J Med Microbiol. 2015;64(8):927-35.

11. Medina-Pascual MJ, Valdezate S, Carrasco G, Villalon P, Garrido N, Saez-Nieto JA. Increase in isolation of Burkholderia contaminans from Spanish patients with cystic fibrosis. Clin Microbiol Infect. 2015;21(2):150-6.

12. Martin M, Christiansen B, Caspari G, Hogardt M, von Thomsen AJ, Ott E, Mattner F. Hospital-wide outbreak of Burkholderia contaminans caused by prefabricated moist washcloths. J Hosp Infect. 2011;77(3):267-70.

13. Ohji G, Ohkusu K, Toguchi A, Otsuka Y, Hosokawa N, Iwata K. Burkholderia contaminans: unusual cause of biliary sepsis. J Infect Chemother. 2013;19(5): 969-71.

14. Moehring RW, Lewis SS, Isaacs PJ, Schell WA, Thomann WR, Althaus MM Hazen KC, Dicks KV, Lipuma JJ, Chen LF, et al. Outbreak of bacteremia due to Burkholderia contaminans linked to intravenous fentanyl from an institutional compounding pharmacy. JAMA Intern Med. 2014;174(4):606-12.

15. Farrell PM. The prevalence of cystic fibrosis in the European Union. J Cyst Fibros. 2008;7(5):450-3

16. Cesarini S, Bevivino A, Tabacchioni S, Chiarini L, Dalmastri C. RecA gene sequence and Multilocus sequence typing for species-level resolution of Burkholderia cepacia complex isolates. Lett Appl Microbiol. 2009:49(5):580-8.

17. Minan A, Bosch A, Lasch P, Stammler M, Serra DO, Degrossi J, Gatti B, Vay C, D'Aquino M, Yantorno O, et al. Rapid identification of Burkholderia cepacia complex species including strains of the novel Taxon $\mathrm{K}$, recovered from cystic fibrosis patients by intact cell MALDI-ToF mass spectrometry. Analyst. 2009;134(6):1138-48

18. Carleton A, Casserly B, Power L, Linnane B, O'flaherty G, Powell J, Hartnett P, Collins J, Murphy P, Kenna D, et al. Clustered multidrug-resistant Bordetella petrii in adult cystic fibrosis patients in Ireland: case report and review of antimicrobial therapies. JMM Case Reports 2014;1(1).

19. Mahenthiralingam E, Vandamme $P$, Campbell ME, Henry DA, Gravelle AM, Wong LT, Davidson AG, Wilcox PG, Nakielna B, Speert DP. Infection with Burkholderia cepacia complex genomovars in patients with cystic fibrosis: virulent transmissible strains of genomovar III can replace Burkholderia multivorans. Clin Infect Dis. 2001:33(9):1469-75.

20. Hall CM, Busch JD, Shippy K, Allender CJ, Kaestli M, Mayo M, Sahl JW, Schupp JM, Colman RE, Keim P, et al. Diverse Burkholderia species isolated from soils in the Southern United States with no evidence of $B$ pseudomallei. PLoS One. 2015:10(11):e0143254

21. da Silva K, Cassetari Ade S, Lima AS, De Brandt E, Pinnock E, Vandamme P, Moreira FM. Diazotrophic Burkholderia species isolated from the Amazon region exhibit phenotypical, functional and genetic diversity. Syst Appl Microbiol. 2012:35(4):253-62.

22. Nannini EC, Ponessa A, Muratori R, Marchiaro P, Ballerini V, Flynn L, Limansky AS. Polyclonal outbreak of bacteremia caused by Burkholderia cepacia complex and the presumptive role of ultrasound gel. Braz J Infect Dis. 2015; 19(5):543-5.

23. Fehlberg LC, Andrade LH, Assis DM, Pereira RH, Gales AC, Marques EA. Performance of MALDI-ToF MS for species identification of Burkholderia cepacia complex clinical isolates. Diagn Microbiol Infect Dis. 2013;77(2): $126-8$.

24. Deng P, Wang X, Baird SM, Showmaker KC, Smith L, Peterson DG, Lu S. Comparative genome-wide analysis reveals that Burkholderia contaminans MS14 possesses multiple antimicrobial biosynthesis genes but not major genetic loci required for pathogenesis. Microbiologyopen. 2016. doi:10. 1002/mbo3.333.

25. Araujo R, Caramalho R, Coutinho C, Sa-Correia I. SNaPBceBcon: a practical tool for identification and genotyping of Burkholderia cepacia and Burkholderia contaminans. J Clin Microbiol. 2016;54(2):483-8. doi:10.1128/ JCM.02476-15. Epub 2015 Dec 9.

26. Ferreira AS, Silva IN, Fernandes F, Pilkington R, Callaghan M, McClean S, Moreira LM. The tyrosine kinase BceF and the phosphotyrosine phosphatase BceD of Burkholderia contaminans are required for efficient invasion and 
epithelial disruption of a cystic fibrosis lung epithelial cell line. Infect Immun. 2015;83(2):812-21.

27. Lu SE, Novak J, Austin FW, Gu G, Ellis D, Kirk M, Wilson-Stanford S, Tonelli M, Smith L. Occidiofungin, a unique antifungal glycopeptide produced by a strain of Burkholderia contaminans. Biochemistry. 2009;48(35):8312-21.

28. Gu G, Smith L, Liu A, Lu SE. Genetic and biochemical map for the biosynthesis of occidiofungin, an antifungal produced by Burkholderia contaminans strain MS14. Appl Environ Microbiol. 2011;77(17):6189-98,

29. Ellis D, Gosai J, Emrick C, Heintz R, Romans L, Gordon D, Lu SE, Austin F, Smith L. Occidiofungin's chemical stability and in vitro potency against Candida species. Antimicrob Agents Chemother. 2012;56(2):765-9.

30. Lupo A, Isis E, Tinguely R, Endimiani A. Clonality and antimicrobial ausceptibility of Burkholderia cepacia complex isolates collected from cystic fibrosis patients during 1998-2013 in Bern, Switzerland. New Microbiol. 2015;38(2):281-8.

Submit your next manuscript to BioMed Central and we will help you at every step:

- We accept pre-submission inquiries

- Our selector tool helps you to find the most relevant journal

- We provide round the clock customer support

- Convenient online submission

- Thorough peer review

- Inclusion in PubMed and all major indexing services

- Maximum visibility for your research

Submit your manuscript at www.biomedcentral.com/submit 